\title{
Associations of early childhood adversities with mental disorders, psychological functioning, and suitability for psychotherapy in adulthood
}

\section{Heinonen, Erkki}

2018-06

Heinonen , E , Knekt , P , Härkänen , T , Virtala , E \& Lindfors , O 2018 , ' Associations of early childhood adversities with mental disorders, psychological functioning, and suitability for psychotherapy in adulthood ' , Psychiatry Research , vol. 264 , pp. 366-373 . https://doi.org/10.1016/j.psychres.2C

http://hdl.handle.net/10138/303667

https://doi.org/10.1016/j.psychres.2018.04.011

publishedVersion

Downloaded from Helda, University of Helsinki institutional repository.

This is an electronic reprint of the original article.

This reprint may differ from the original in pagination and typographic detail.

Please cite the original version. 


\title{
Associations of early childhood adversities with mental disorders, psychological functioning, and suitability for psychotherapy in adulthood
}

\author{
Erkki Heinonen $^{\mathrm{b}, *}$, Paul Knekt ${ }^{\mathrm{a}}$, Tommi Härkänen ${ }^{\mathrm{a}}$, Esa Virtala ${ }^{\mathrm{a}}$, Olavi Lindfors ${ }^{\mathrm{a}}$ \\ a National Institute for Health and Welfare, Mannerheimintie 166, Helsinki, Finland \\ ${ }^{\mathrm{b}}$ University of Helsinki, Finland
}

\section{A R T I C L E I N F O}

\section{Keywords:}

Depression

Anxiety

Childhood adversities

Psychotherapy

Personality

Psychosocial function

\begin{abstract}
A B S T R A C T
Childhood adversities frequently precede adulthood depression and anxiety. Yet, how they impact needed treatment duration, type or focus in these common disorders, is unclear. For developing more individualized and precise interventions, we investigated whether specific early adversities associate with patients' distinct psychiatric problems, psychological vulnerabilities, and suitability for psychotherapy. A total of 221 depressed and anxious adult outpatients (excluding psychotic, severe personality, bipolar, and substance abuse disorders) referred from community, student, occupational, and private healthcare services filled the Childhood Family Atmosphere Questionnaire (CFAQ). They also filled self-reports on interpersonal behavior and problems, perceived competence, dispositional optimism, sense of coherence, defenses, and psychiatric history. Clinicians assessed the patients' symptomatology, personality, object relations, cognitive performance, and psychotherapy suitability. Regression analyses were conducted. Childhood adversities predicted both worse current psychological functioning (e.g., interpersonal problems), and better clinician-rated capacities for benefiting from psychotherapy (e.g. self-reflection, capacity for interaction). Parental problems had the most numerous negative associations to psychological functioning. Best capacities for psychotherapy were predicted by recollected family unhappiness. Associations with psychiatric criteria were, however, largely non-significant. In conclusion, for psychosocial treatment planning, patients' early adversities may indicate both vulnerability and resources. As childhood adversities are frequent among treatment-seekers, further studies examining how early adversities predict psychotherapy outcome are needed.
\end{abstract}

\section{Introduction}

Childhood adversities - such as early separation from caregivers, emotional neglect, physical and sexual abuse, parental problems, and overall family unhappiness - are robustly associated with depression, anxiety, and other psychiatric problems in adulthood (Edwards et al., 2003; Gilbert et al., 2009). Mechanisms behind this consistent observation from both prospective and retrospective studies are still not well-known (Kaufman, 2012). The pathways to pathology may be influenced by numerous intra-individual and environmental factors and their interaction during development. These factors may include internalizing negative cognitions regarding the self and others (Wright et al., 2009); compromised emotional regulation (van Harmelen et al., 2013; Vu et al., 2016); lack of modeling opportunities for behavioral coping skills (Vu et al., 2016); and genetic and neurobiological vulnerabilities, in concert with epigenetic processes (Danese and McEwen, 2012; McCrory et al., 2010). While all these factors may operate during early life course and precipitate psychiatric problems, it is pertinent to remember that the influences may be two-way and not exclude each other: acute problems in adulthood, such as depression and anxiety, may also increase recall of negative memories of childhood (Williams et al., 2007).

Whether precipitated by adverse early experiences or not, psychiatric disorders typically emerge during youth and adulthood. They are commonly treated by psychotherapy, pharmacotherapy or their combination. Yet while childhood adversities are relatively frequent among treatment-seekers (Edwards et al., 2003), their treatment implications are still unclear (Kaufman, 2012; Korotana et al., 2016). For instance, do early adversities indicate the need for more intense or longer-term treatment? Childhood adversities and their greater duration, frequency, and severity have been linked with more severe and chronic psychiatric disturbances (Gilbert et al., 2009). These in turn are often seen to require longer treatment (Nanni et al., 2011; Perry et al., 2007). These associations might be observed especially in serious breaches of caregiving, such as a child's direct physical or sexual abuse. However, many psychological consequences of childhood adversities may not be gauged

\footnotetext{
* Corresponding author.

E-mail address: erkki.heinonen@thl.fi (E. Heinonen).
} 
by explicit psychiatric criteria, such as symptoms, diagnoses, or treatment history. Instead, they may be observable via subtler psychological measures, which also impact treatment outcome and selection. For instance, varied psychological strengths and vulnerabilities in personality-related (e.g. dispositional optimism, self-concept) (Heinonen et al., 2017; Lindfors et al., 2014), affective (e.g., defenses) (Laaksonen et al., 2014), and cognitive (e.g. intelligence) (Knekt et al., 2014), domains have also predicted whether brief psychotherapies suffice or long-term therapy is indicated. Yet few studies have explored how childhood adversities are associated with such psychological factors.

Mapping how different childhood adversities are associated with such psychological attributes in adulthood might also help answer another important question: What is the treatment focus? For instance, persons who have suffered early adversities typically harbor more negative cognitions toward both their adult self and the environment (van Harmelen et al., 2013; Wright et al., 2009). Modifying such specific interpretations and biases has in turn been suggested as central to both effecting recovery as well as preventing relapses in disorders such as depression or anxiety (Williams et al., 2007). To gear interventions more effectively towards such psychological issues which may uphold present distress, however, more knowledge is still needed on how they link with various childhood adversities that patients often disclose. Especially when assessed retrospectively, stronger associations to psychological variables might be expected with adversities that reflect explicitly negative recollections of childhood (e.g., unhappy family atmosphere) than those which are essentially neutral (e.g., early separation from caregivers), or whose impact (e.g., parental problems) may have been mitigated by other factors, such as other available environmental support.

Yet childhood adversities need not only be associated with psychological vulnerabilities. Early hardships and their recognition may also serve as motivation to work through one's problems; difficult circumstances may sometimes lead to development of adaptive intrapersonal and relational capacities (Shiner and Masten, 2012). Thus, treatment planning should be enhanced by identifying both the psychological resources and vulnerabilities that childhood adversities may bring. In line with calls for "precision medicine" in psychiatry (Insel, 2014), this knowledge might facilitate more effective, individualized treatment than enabled by current diagnostic categories alone. Toward this aim, the present exploratory study investigates how childhood adversities are associated with various psychiatric problems and psychological vulnerabilities and resources in a sample of depressed and anxious adult outpatients.

Despite the essentially exploratory nature of our investigation, broad expectations were formed as outlined above and summarized here: 1) Greater childhood adversities are associated with greater or more severe psychiatric symptomatology, co-morbidity, and treatment history. These associations might be expected especially with severe and direct breaches of care-giving, such as a child's physical or sexual abuse. 2) "Lesser" childhood adversities might not show associations with explicitly psychiatric criteria. However, their impact might be picked up by subtler psychological measures. More associations might be expected with explicitly negative recollections of childhood (e.g., unhappy family atmosphere), and also the aforementioned serious breaches of care-giving (e.g., child abuse). However, fewer associations might be shown by i) essentially neutral occurrences (e.g., separations from caregivers), or ii) factors whose impact (e.g., parental problems) may have been mitigated by other factors, such as the availability of other environmental support.

\section{Methods}

The data was collected as a part of the Helsinki Psychotherapy Study (HPS), a clinical trial evaluating the effectiveness of short- and longterm psychotherapies in the treatment of depressive and anxiety disorders (Knekt et al., 2016; Knekt and Lindfors, 2004). The current study is based on data assessed at baseline before randomization into treatments. None of the analyses presented here have been published previously.

\subsection{Patients}

Overall 580 outpatients from the Helsinki region were recruited from psychiatric services between June 1994 and June 2000. Local psychiatrists were informed about the trial. They carried out the first phase screening by referring to the trial patients who were evaluated to fulfill the inclusion criteria and be suitable for the treatments. The psychiatrists worked in private practice $(29 \%)$, and primary $(16 \%)$, student (20\%), occupational (10\%), and community mental health care $(10 \%)$. The patients represented individuals normally treated by psychotherapy in southern Finland.

Eligible patients met DSM-IV criteria for anxiety or mood disorder (APA 1994), had a long-standing ( $>1$ year) disorder causing work dysfunction, and were 20-45 years of age. Excluded were patients with psychotic, bipolar I, severe personality, adjustment, substance abuse or organic disorder. Also excluded were individuals treated with psychotherapy within the previous 2 years, psychiatric health employees, and persons known to the research team members.

Out of the 326 patients eligible for the trial, this study is based on the first 221 individuals whose childhood adversities were assessed with a questionnaire and interview (this questionnaire was later excluded to make the assessment process more efficient). The patients gave informed consent. The study follows the Helsinki Declaration and was approved by the Helsinki University Central Hospital ethics council.

\subsection{Assessors}

The observer-rated pre-treatment assessments were carried out by seven interviewers (two psychiatrists and five psychologists) over the course of three 45-minute semi-structured interviews for each patient (Knekt et al., 2012; Valkonen et al., 2012). The interviewers had relatively extensive clinical experience (range 9 to 20 years) and were given additional training (60-100 hours, over a period of 4-6 months) for the assessments relevant to the present study.

\subsection{Measures}

\subsubsection{Assessment of childhood adversities}

2.3.1.1. The Childhood Family Atmosphere Questionnaire (CFAQ). The Childhood Family Atmosphere Questionnaire (CFAQ) is a 17-item selfreport questionnaire for adults concerning one's childhood. It was developed in the HPS to assess the significance of childhood adversities when planning for psychotherapy. The questionnaire was informed by family, trauma, and attachment research. The CFAQ solicits information on parental problems (marital, mental, economic, alcohol-related, physical health), sexual and physical abuse, and parental care and family relations and atmosphere under the age of 8 years. The items are scored from 1 to 5 ("I totally agree", "I agree", "I do not know", "I do not agree", and "I definitely do not agree"). Some variables were reverse-scored so that the direction for negative and positive family ratings would be the same. Based on the items' content and ensuring the scales' internal validity by factor analysis, three aggregate scores were formed of the items by averaging them and named Parental Problems (8 items), Abuse During Childhood (3 items), and Family Unhappiness (6 items) (see Appendix I).

2.3.1.2. Early separations. Early separations from caregivers were rated separately in interview, from 1 ("No significant separations") to 7 ("Loss of both parents or suicide by either").

2.3.1.3. Repeatability of CFAQ. The repeatability of the CFAQ was evaluated in a sub-population of 172 patients, who completed the 
questionnaire both at baseline and 8-12 years later, after participating in psychotherapy. Despite the long time lag and the potential effects of psychotherapy on recollection of childhood events, the scales' repeatability was in the 'fairly good' range, the reliability coefficient (Winer, 1971) being 0.75 for Family Unhappiness, 0.79 for Parental Problems, and 0.79 for Abuse During Childhood; and the respective kappa values being.73, 0.68 , and 0.75 .

\subsubsection{Other measures}

2.3.2.1. Psychological functioning. The present study explored various domains of psychological functioning that could be affected by childhood adversities. The concepts explored related to numerous theoretical models on varying levels of abstraction; using different methods of operationalization; and many of which have been investigated as either predictors or response variables in this trial. Interview-based, observer-rated, reliable and valid assessment methods were used to gauge level of personality organization (LPO) (Kernberg, 1984; Knekt et al., 2017; Valkonen et al., 2012) and quality of object relations (QORS) (Azim and Piper, 1991; Lindfors et al., 2013). Selfrated, reliable and valid questionnaires were used to solicit information on the patients' defense style (use of immature defenses) (DSQ) (Andrews et al., 1993; Laaksonen et al., 2014), self-concept (SASB) (Benjamin, 1996; Lindfors et al., 2013), interpersonal problems (IIP) (Horowitz et al., 2000; Ollila et al., 2016), perceived competence (Knekt et al., 2016; Wallston, 1990), sense of coherence (SOC) (Antonovsky, 1993; Knekt et al., 2016), and dispositional optimism (LOT) (Heinonen et al., 2017; Scheier and Carver, 1985). A performance-based test was used to measure cognitive performance (WAIS) (Knekt et al., 2014; Wechsler, 1981).

2.3.2.2. Suitability for psychotherapy variables. Capacities for psychotherapeutic work were assessed with the interview-based Suitability for Psychotherapy Scale (SPS) (Laaksonen et al., 2012). The clinician-rated SPS has been found reliable and valid for predicting outcome in short- and long-term therapy representing different theoretical orientations (Laaksonen et al., 2013a,2013b). The scale comprises three general domains, consisting of seven subdomains: selfobserving capacity (consisting of reflective ability, motivation for psychotherapy, and reaction to trial interpretation), ego strength (consisting of flexibility of interaction, capacity to modulate affects, and self-concept in relation to ego ideal), and the degree to which a patient's problems may be conceptualized as having a circumscribed, clearly identifiable focus (Laaksonen et al., 2012).

2.3.2.3. Current psychiatric problems and global functioning. Diagnoses were based on DSM-IV criteria (APA, 1994). They were evaluated based on the semi-structured interview also used to assess the other aspects of psychological functioning and suitability for psychotherapy. For quality assurance, their reliability was assessed in a subsample of patients by comparison to diagnoses based on the Structured Clinical Interview (SCID), and found to be satisfactory. Current psychopathological symptoms were assessed with the Symptom Checklist 90 self-report which yields scores for overall symptoms (SCL-90-GSI), depression (SCL-90-DEP), and anxiety (SCL-90-ANX) (Derogatis et al., 1973), and Beck Depression Inventory (BDI) (Beck et al., 1961). Also, observers rated depressive symptoms with the Hamilton Depression Rating Scale (HDRS) (Hamilton, 1960), anxiety with the Hamilton Anxiety Rating Scale (HARS) (Hamilton, 1959), and patient's general level of functioning with the General Assessment of Functioning scale (GAF) (APA, 1994).

2.3.2.4. Psychiatric history. Information on earlier episodes of major depressive disorder, onset of first psychiatric disorder, duration of primary psychiatric disorder, suicide attempts, previous psychotherapy and psychotropic medication was solicited with baseline questionnaires developed in the trial (Knekt and Lindfors, 2004).
2.3.2.5. Socio-economic factors. Socio-economic factors (sex, age, marital status, and education) were assessed at baseline using questionnaires developed in the trial (Knekt and Lindfors, 2004). Education was assessed on a four-point scale (1 = academic education, $2=$ vocational education, $3=$ high school graduate, $4=$ primary school). Marital status was assessed on a three-point scale $(1=$ single, $2=$ cohabiting or married, $3=$ separated, divorced, or widowed).

\subsection{Statistical methods}

Linear regression models were used for the analyses. In a basic model, the independent variable was the CFAQ factor as a continuous variable and, in a second model, as a categorized variable. The categorization was conducted because of the potential non-linearity of the associations (Breslow and Day, 1980). The dependent variable was the psychiatric or psychological problem, vulnerability, or resource of interest (continuous or dichotomous). Based on the basic model, regression coefficients, variance explained, and P-values for trend were calculated. In the second model, means of the dependent variables were estimated in the categories of the independent variable. Different categorization of the independent variables was used when exploring associations with psychiatric versus when exploring psychological dependent variables, due to the specific research interests regarding these two domains. In exploring the psychiatric outcome variables, on which relatively more prior research exists, the CFAQ factor scores were divided according to the median. In exploring the psychological outcome variables (including psychotherapy suitability), the CFAQ factor scores were categorized according to the quartile, with the highest quartile compared against the lower ones. This was based on the expectation that insofar as early adversities do make a meaningful difference for psychological domains that may have treatment implications in depression and anxiety, they would most likely be observed when examining significant amounts of such early adversities. Early separations were categorized correspondingly in these two domains either by the midpoint (i.e., 4) or by the higher-end value of 6 when looking at psychiatric or psychological dependent variables, respectively. The significance level 0.05 was used. Because of the multiple comparisons performed, also the corresponding Bonferroni corrected level 0.003 was used in secondary comparisons.

All statistical analyses were performed with SAS software, version 9.1 .

\section{Results}

\subsection{Descriptive results}

About three fourths of the population were female and without academic education (Table 1). The mean age was 32 years and about half were living alone. Approximately four fifths suffered from depressive disorder, one half from anxiety disorder, and a quarter from personality disorder and/or both depressive and anxiety disorder. Roughly a third had experienced early separations from one or both parents. Also other early problems were fairly common. Table 2 reports the means, standard deviations, and proportions of the dependent variables (psychological functioning, suitability for psychotherapy, psychopathological symptomatology, global functioning, and psychiatric history).

\subsection{Psychological functioning}

More significant or numerous childhood separations and/or their threat predicted more sense of autonomy (Table 3). Experienced family unhappiness in childhood predicted less sense of autonomy and greater present interpersonal problems. Recollected problems between parents predicted lower level of personality organization, less mature object 
Table 1

Sociodemographic, diagnostic, and early childhood characteristics of the overall sample $(N=221)$.

\begin{tabular}{ll}
\hline Sociodemographic factors & Mean (SD) \\
\hline Male (\%) & 27.2 \\
Age (years) & $32.3(6.96)$ \\
Single (\%) & 49.3 \\
Academic education (\%) & 23.5 \\
Psychiatric diagnoses & \\
Mood disorder (\%) & 78.7 \\
Severe major depressive disorder, single episode (\%) & 23.5 \\
Severe major depressive disorder, recurrent (\%) & 37.6 \\
Other mood disorder (\%) & 21.7 \\
Anxiety disorder (\%) & 48.0 \\
Social phobia (\%) & 19.5 \\
Generalized anxiety disorder (\%) & 9.5 \\
Panic disorder (\%) & 7.7 \\
Obsessive-compulsive disorder (\%) & 2.7 \\
Other anxiety disorder, NOS (\%) & 12.7 \\
Comorbid mood and anxiety disorder (\%) & 26.7 \\
Personality disorder (\%) & 23.1 \\
Cluster B personality disorder (\%) & 2.3 \\
Cluster C personality disorder (\%) & 5.0 \\
Personality disorder, NOS (\%) & 15.8 \\
Childhood family atmosphere & \\
Early separations (\% "high") & 30.8 \\
Family unhappiness & $2.80(0.90)$ \\
Parental problems & $3.75(0.78)$ \\
Childhood abuse & $3.77(1.04)$ \\
\hline
\end{tabular}

a "High": $\geq 6$. Parents' divorce or death.

Table 2

Psychological functioning, suitability for psychotherapy, psychopathological symptoms and global functioning, and psychiatric history of the overall sample $(N=221)$.

\begin{tabular}{ll}
\hline Psychological functioning & \\
Level of personality organization & $4.18(0.69)$ \\
Quality of object relations & $5.08(0.61)$ \\
Defense style questionnaire & $3.89(0.73)$ \\
SASB Autonomy & $-28.9(35.4)$ \\
SASB Affiliation/Love & $8.90(60.3)$ \\
Interpersonal problems & $86.3(30.7)$ \\
Perceived competence & $30.7(6.85)$ \\
Sense of coherence & $114.5(20.3)$ \\
Dispositional optimism & $17.2(5.5)$ \\
WAIS-R & $110.0(10.3)$ \\
Suitability for psychotherapy & \\
Modulation of affects & $2.95(1.13)$ \\
Capacity for self-reflection & $2.78(1.01)$ \\
Flexibility of interaction & $2.71(1.19)$ \\
Reaction to trial interpretation & $3.97(1.22)$ \\
Self-concept in relation to ego ideal & $3.47(1.11)$ \\
Circumscribed focus & $3.21(1.30)$ \\
Motivation & $2.80(0.98)$ \\
Total SPS score & $2.33(1.75$ \\
Psychopathological symptoms and global functioning & \\
Self-rated & \\
SCL-90-GSI & \\
BDI & $1.25(0.51)$ \\
SCL-90-DEP & $17.7(7.87)$ \\
SCL-90-ANX & $1.96(0.75)$ \\
Observer-rated & $1.22(0.67)$ \\
HDRS & \\
HARS & $15.3(4.60)$ \\
Global assessment of functioning (GAF) & $14.7(5.24)$ \\
Psychiatric history & $55.3(7.33)$ \\
Earlier severe depressive episodes (\%) & \\
Onset of 1. psychiatric disorder before the age of 22 years (\%) & 61.9 \\
Duration of primary mental disorder over 5 yrs. (\%) & 63.7 \\
Suicide attempts (\%) & 32.1 \\
Hospitalized for psychiatric reasons (\%) & 9.2 \\
Previous psychotherapy (\%) & 1.36 \\
Earlier psychotropic medication (\%) & 22.4 \\
\hline & \\
\hline & \\
\hline & \\
\hline
\end{tabular}

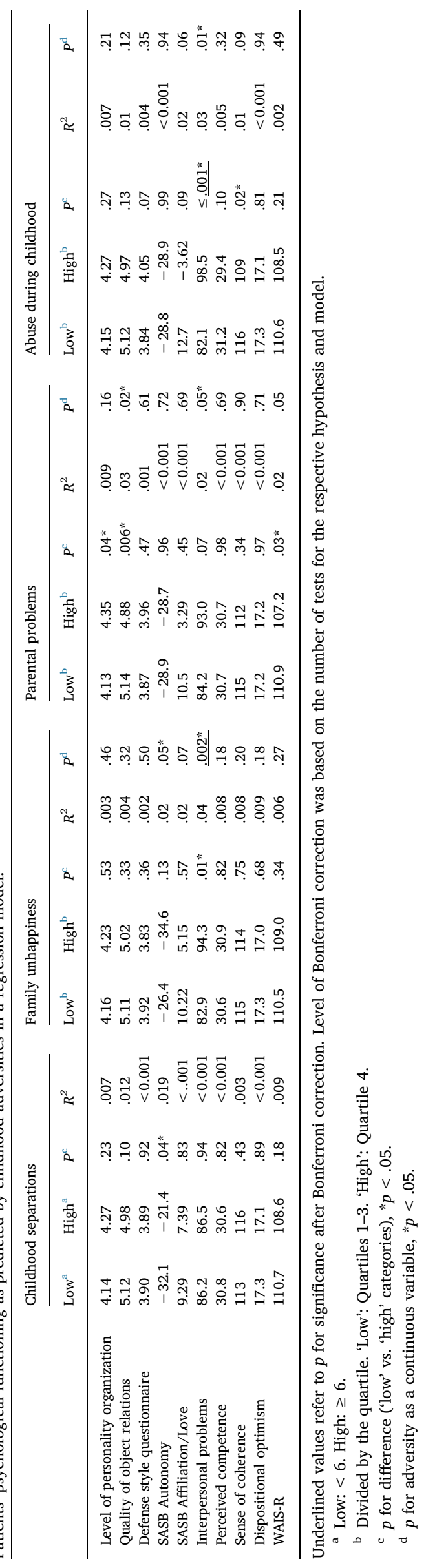


Table 4

Patients' suitability for psychotherapy as predicted by childhood adversities in a regression model.

\begin{tabular}{|c|c|c|c|c|c|c|c|c|c|c|c|c|c|c|c|c|c|c|c|}
\hline \multirow{2}{*}{$\begin{array}{l}\text { Suitability for } \\
\text { Psychotherapy Scale (SPS) } \\
\text { domains }^{\text {a }}\end{array}$} & \multicolumn{4}{|c|}{ Childhood separations } & \multicolumn{5}{|c|}{ Family unhappiness } & \multicolumn{5}{|c|}{ Parental problems } & \multicolumn{5}{|c|}{ Abuse during childhood } \\
\hline & Low $^{\mathrm{b}}$ & $\operatorname{High}^{\mathrm{b}}$ & $P^{\mathrm{d}}$ & $R^{2}$ & Low $^{c}$ & $\operatorname{High}^{\mathrm{c}}$ & $P^{\mathrm{d}}$ & $R^{2}$ & $p^{\mathrm{e}}$ & Low $^{c}$ & $\operatorname{High}^{c}$ & $P^{\mathrm{d}}$ & $R^{2}$ & $p^{\mathrm{e}}$ & Low $^{c}$ & $\operatorname{High}^{c}$ & $P^{\mathrm{d}}$ & $R^{2}$ & $p^{\mathrm{e}}$ \\
\hline Modulation of affects & 2.89 & 3.09 & .24 & .006 & 3.01 & 2.82 & .24 & .017 & .06 & 2.94 & 3.00 & .74 & .001 & .62 & 2.95 & 2.96 & .95 & .002 & .56 \\
\hline Capacity for self-reflection & 2.81 & 2.74 & .62 & .001 & 2.90 & 2.52 & $.01 *$ & .05 & $\leq .001^{*}$ & 2.87 & 2.51 & $.02 *$ & .02 & $.05^{*}$ & 2.81 & 2.71 & .52 & $<0.001$ & .83 \\
\hline Flexibility of interaction & 2.76 & 2.60 & .36 & .004 & 2.84 & 2.42 & $.02^{*}$ & .04 & $\leq .001^{*}$ & 2.81 & 2.40 & $.03^{*}$ & .02 & $.04 *$ & 2.78 & 2.51 & .14 & .006 & .27 \\
\hline $\begin{array}{l}\text { Reaction to trial } \\
\text { interpretation }\end{array}$ & 3.91 & 4.13 & .21 & .007 & 3.97 & 3.98 & .95 & $<0.001$ & .91 & 3.96 & 4.02 & .78 & $<0.001$ & .88 & 3.99 & 3.95 & .82 & $<0.001$ & .76 \\
\hline $\begin{array}{l}\text { Self-concept in relation to } \\
\text { ego ideal }\end{array}$ & 3.48 & 3.44 & .81 & $<0.001$ & 3.50 & 3.38 & .47 & $<0.001$ & .88 & 3.46 & 3.49 & .87 & .003 & .45 & 3.47 & 3.47 & .97 & $<0.001$ & .93 \\
\hline Circumscribed focus & 3.17 & 3.32 & .42 & .003 & 3.37 & 2.86 & $.008^{*}$ & .09 & $\leq .001 *$ & 3.25 & 3.11 & .50 & .02 & $.05^{*}$ & 3.29 & 3.00 & .15 & .02 & .05 \\
\hline Motivation & 2.80 & 2.81 & .64 & .001 & 2.90 & 2.57 & $\overline{.02 *}$ & .04 & $\leq \overline{.003^{*}}$ & 2.87 & 2.58 & .07 & .02 & $.04 *$ & 2.88 & 2.55 & $.03^{*}$ & .02 & $.04 *$ \\
\hline Total SPS score & 2.26 & 2.53 & .29 & .005 & 2.50 & 1.95 & $.03 *$ & .03 & $.02^{*}$ & 2.46 & 1.98 & .09 & .01 & .10 & 2.42 & 2.11 & .26 & .006 & .27 \\
\hline
\end{tabular}

Underlined values refer to $p$ for significance after Bonferroni correction. Level of Bonferroni correction was based on the number of tests for the respective hypothesis and model.

a Lower values indicate better suitability for psychotherapy.

b Low: <6. High: $\geq 6$.

c Divided by the quartile. 'Low': Quartiles 1-3. 'High': Quartile 4.

d $p$ for difference ('low' vs. 'high' categories), * $p<.05$.

e $p$ for adversity as a continuous variable, ${ }^{*} p<.05$.

relations (i.e., being closer to the borderline personality stage), greater interpersonal problems, and lower cognitive performance. Greater abuse during childhood predicted greater interpersonal problems and less sense of coherence in the present day. After Bonferroni correction, family unhappiness and childhood abuse significantly predicted greater interpersonal problems.

\subsection{Suitability for psychotherapy variables}

A higher capacity for self-reflection and flexible interaction, as well as better treatment focus and motivation, were predicted by greater recollected family unhappiness and problems between parents (Table 4). Better motivation was also predicted by greater childhood abuse. In addition, better total suitability for psychotherapy was predicted by greater recollected family unhappiness. After Bonferroni correction, family unhappiness significantly predicted self-reflection, flexible interaction, focus and motivation.

\subsection{Current mental disorders, psychopathological symptoms, and global functioning}

None of the CFAQ areas were statistically significantly associated with psychiatric diagnoses or co-morbidity (i.e., whether patients had only mood or anxiety disorder or both together; a major depressive disorder; or a co-morbid personality disorder) (data not shown). Associations with psychopathological symptoms and global functioning were also non-significant, with the exception of family unhappiness, which predicted less observer-rated anxiety symptoms (Supplementary Table 1, Appendix). After Bonferroni correction, no significant associations remained.

\subsection{Psychiatric history}

Greater family unhappiness predicted more likely earlier severe depressive episodes. Greater parental problems predicted greater likelihood of the onset of first psychiatric disorder before the age of 22 years and previous psychotherapy (Supplementary Table 2, Appendix). After Bonferroni correction, no significant associations remained.

\section{Discussion}

As Tolstoy (1954) famously observed, "Happy families are all alike; every unhappy family is unhappy in its own way" . Our exploratory study contributes importantly to understanding the implications of such diverse unhappiness which befalls different families. This was done by examining the associations between various kinds of adversities in childhood and an exceptionally broad array of their psychiatric and psychological correlates in adulthood. While associations to psychiatric criteria were largely non-significant, systematical associations were observed between current psychological distress and early childhood adversities. Interestingly, however, different kinds of adversities seemed to have specific types of harmful repercussions. Yet more interestingly, the implications are not all bleak: many recollected early hardships also indicated significant resources for psychotherapeutic work.

\subsection{Early childhood adversities' associations to psychiatric variables}

It should first be noted that the associations of different childhood adversities with explicitly psychiatric criteria - such as symptoms, comorbidity and psychiatric history - were far fewer than in some previous studies (Gilbert et al., 2009). The overall lack of expected psychiatric associations may be attributable to the sample being somewhat homogeneous and restricted from "both ends". That is, the sample consisted of clinically depressed and anxious rather than also nonsymptomatic adults, while excluding patients with more severe problems (e.g., severe personality, substance abuse, and psychotic disorders). Regardless, our confidence in the finding from this population is strengthened by the fact that psychiatric problems were rated by both patients and observers. One implication for the clinician may thus be that while depressed and anxious patients who present for treatment may recollect various early adversities, such early hardships do not automatically implicate these patients to be psychiatrically more severe cases than patients without them.

\subsection{Early childhood adversities' associations to psychological problems}

While associations to explicitly psychiatric criteria were scarce and inconsistent, greater childhood adversities were associated systematically with greater psychological problems. The most numerous detrimental influences seemed to be had by parental problems. These problems of caregivers could range from economic difficulties and volatile atmosphere at home to parents' somatic illness, substance abuse, and mental health issues. Notably, their potential impact was seen across observational and 
methodological perspectives. They were associated with (observer-rated) lower-level personality organization and less mature object relations, (testbased) lower cognitive performance, and more (patient-rated) interpersonal problems in adulthood. Of these, lower personality organization, less mature object relations, and greater interpersonal difficulties together suggest more profound problems with the self, other people, and their boundaries. These can be plausibly viewed as arising from a psychologically insecure environment, where trust in others may be hard to develop; need to regulate one's emotions and behavior alone intensify; and the risk for selfblame and feeling unworthy increase (Bowlby, 1969; Cicchetti and Doyle, 2016). In adulthood, such past experiences and issues may understandably make it more difficult to develop a trusting working relationship with one's clinician. Accordingly, a clinician stance that communicates safety, acceptance, and collaboration, as well as willingness to explore and address any ruptures in the relationship, may be particularly important (Herman, 2008; Kolk and Fisler, 1994; Safran and Kraus, 2014; Safran and Muran, 2000). Domestic instability may also lead to the observed lower cognitive performance by, e.g., most concretely, disrupting concentration on schoolwork (Vu et al., 2016). However, the potential pathways behind this association are numerous, on both the environmental and the neurological levels, and further studies are needed to shed light on these (e.g. Dannehl et al., 2017; Friesen et al., 2017; Gilbert et al., 2009; Jacobsen et al., 1994).

Other childhood adversities (i.e. family unhappiness, childhood separations, and physical and sexual abuse) had somewhat less widely harmful associations. First, family unhappiness was associated with both lesser sense of autonomy and greater interpersonal problems. This may reflect continuity between childhood relationships, internalized relationship images, and present problematic interaction, as suggested by attachment, object relational, and modeling theories (Bartholomew and Horowitz, 1991; Cicchetti and Doyle, 2016). However, this factor focuses more on the 'tenor' of family atmosphere than objective or concrete events or problems. Hence, it is hard to judge to what degree this association represents the prospective impact of actual childhood unhappiness, and to what degree the negative affective coloring of childhood recollections, as influenced by current problems in relationships (Williams et al., 2007). Despite this caveat, many therapeutic orientations suggest exploring potential connections between past and present relationships, whether through psychodynamic interpretation and insight (cf. Shedler, 2010), cognitive techniques (cf. Dienes et al., 2011), or experiential means (cf. Greenberg and Malcolm, 2002); further, their similar outcomes suggest all these approaches may be equally effective (Lambert, 2013). Although causality cannot be concluded, it may be noted that the association of childhood adversities to interpersonal problems was robust, remaining significant also after correction for multiple comparisons.

Childhood separations, in turn - which might be expected to be rated more reliably, whether due to parents' demise or divorce - were associated with a greater sense of autonomy. While the clinical implication of this finding is not clear, it seems expectable that early separations from caregivers may have put more pressure to depend on oneself, whether for better or worse (Bowlby, 1969). Finally, physical or sexual abuse during childhood was associated with greater interpersonal problems and less sense of coherence in the present day. These problems in relationships and, more generally, in experiencing the world as controllable, sensible, and meaningful could understandably arise from the inherent conflict in reconciling the conception of one's primary caregivers (i.e., the typically most important source of safety and support) as also a serious threat to one's self and boundaries. Addressing the above-mentioned fundamental deprivations of agency, trust, and security is likewise a delicate task in treatment. To promote patients' distinction between early helplessness and current mastery, trauma literature has emphasized the need to balance holding and containment with exploring affects and past memories (Kolk and Fisler, 1994).

In sum, therefore, the findings appear to suggest different childhood adversities may have quite specific and meaningful psychological consequences. While the many measures of psychological distress often correlate (Hill and Lambert, 2004), clearly the specific problems predicted by different adversities in this study are not identical with each other. Quite plausibly, therefore, knowing a person's childhood adversities may also be important to addressing her present psychological problems in adulthood, whether manifested diagnostically as, e.g., depression or anxiety. Indeed, psychotherapeutic literature suggests varied ways to address the problems associated with these early adversities. Therefore, it is also an important question how these early adversities predict various patient capacities for benefitting from psychotherapy.

\subsection{Early childhood adversities' associations to psychotherapy suitability variables}

As perhaps the most interesting finding, recollected childhood adversities predicted better observer-rated psychotherapy suitability in its various domains. Early family unhappiness was associated the most domains: i.e., greater capacity for self-reflection and interaction, better treatment motivation, a clearer treatment focus, and better overall suitability. These associations were also clearly the most robust, majority of them being significant also in the Bonferroni-corrected secondary analyses. Furthermore, as noted earlier, in the domain of psychological problems childhood family unhappiness was associated only with less sense of autonomy and greater current interpersonal problems. Hence it seemed like the most "benign" childhood adversity to have. Indeed, its rating perhaps reflected partly a kind of psychological mindedness and awareness into the past determinants of one's current problems often considered useful for psychotherapeutic work (cf., Herman and Harvey, 1997; Laaksonen et al., 2012). It is even possible that patients who appeared to clinicians as minimizing early familial unhappiness were considered as more challenging to work with. However, this possibility would best be investigated in a design where, additionally, collateral measures of "objective" childhood adversities (e.g., from siblings or health care records) could be compared with patients' subjective adulthood recollections.

Parental problems likewise were associated with better self-reflection, problem focus, and motivation for psychotherapy. Somewhat surprisingly in view of their other associations, they were also associated with more flexible interaction in the assessment for psychotherapy. Hence it appears that although parental problems also had clearly negative psychological associations (greater interpersonal problems, lower personality organization, and less mature object relations), they do not present insurmountable, clinician-assessed obstacles to begin psychotherapy, but rather vice versa. They perhaps represent sufficient suffering to be worked on in psychotherapy, especially in the context of adequate self-reflection and recognition of the important past determinants of one's psyche (Ollila et al., 2016). In other words, such problems may even be conducive to building the type of relationship pertinent to psychotherapy. What matters more, then, than the parents' actual problems may be the capacity to access negative aspects of childhood (Herman and Harvey, 1997).

Childhood adversities, or at least their recognition, thus appear clearly associated with capacities for psychotherapy. Previous studies have found these capacities conducive to benefiting sufficiently from brief psychotherapy representing different theoretical models (Laaksonen et al., 2013b). Their lack, in contrast, has indicated the need for longer psychotherapy (Laaksonen et al., 2013a). Given the size of effects, the present findings do not allow for recommendations regarding clinical psychotherapy practice. Nevertheless, given the number of these associations, they clearly indicate an important question for future research is: How do these childhood adversities predict outcome in different short-term and long-term psychotherapies?

\subsection{Methodological considerations and limitations}

The study had several strengths. First of all, the sample represented typical treatment-seekers who had contacted typical different services (community mental health and student health care, occupational health care, psychiatry policlinics, and private practitioners). Second, even 
modest effects could be identified with this relatively large sample. Third, the CFAQ-questionnaire has good face and content validity, being in line with previous empirical and theoretical literature (Gilbert et al., 2009). Fourth, the internal validity of the CFAQ factors was assessed to be satisfactory. Fifth, the repeatability of CFAQ was fairly good even over a lengthy interval of 8-12 years and an intervening psychotherapeutic intervention. Sixth, the correlates of early childhood adversities were assessed with validated and reliable measures on which a large body of research literature exists.

However, the study also had some limitations. First, since psychotic, bipolar, substance abuse, and severe personality disorders were screened out, findings of this exploratory study may not generalize to those populations. Accordingly, further confirmatory studies with other populations and adversity measures should be conducted to establish the generality of these findings. Second, given the retrospective and uncontrolled nature of this study, causal conclusions cannot be made. However, given the complexity of this area, it may be noted that even prospective studies often cannot conclusively rule out confounding factors (Kaufman, 2012). Third, more specifically, recall bias is obviously possible: i.e. remembering childhood negatively due to current psychiatric problems (Williams et al., 2007). However, both our own and other investigations suggest childhood adversities may be quite reliably recalled even over long periods of time (Nanni et al., 2011). Further, for treatment implications, what is currently recalled may be as important as what "actually" happened, and this should be investigated in future studies. Finally, examining numerous associations would expectably yield some chance findings. However, after Bonferroni-corrections had been made, significant findings were still observed for several factors and psychological domains (although very clearly only for one, i.e., the association of family unhappiness with suitability for psychotherapy).

Appendix. Childhood Family Atmosphere Questionnaire

\subsection{Conclusions}

The present study indicated that depressed and anxious patients who report more childhood adversities - in the absence of substance abuse, psychotic and other severe disorders - do not report significantly more psychiatric symptoms, co-morbidity, or psychiatric history. However, these patients do experience more psychological problems on a variety of domains and as rated from various viewpoints. These harmful repercussions were observable especially in interpersonal functioning and representations of self and others, although other domains (e.g., self-rated sense of competence, optimism, defenses) were not affected. Yet patients who identify childhood adversities, especially family unhappiness, appear to also have more psychological resources for psychotherapeutic work. The findings of this exploratory study should be confirmed by further investigations. However, as patients with childhood adversities represent a typical population seeking psychotherapy, future investigations should also investigate how these childhood adversities may predict outcomes of psychotherapies of different lengths and orientations.

\section{Acknowledgments}

The Helsinki Psychotherapy Study Group was responsible for collection of the data. Mr. Julius Rissanen is acknowledged for help in conducting the statistical analyses.

Conflicts of interest: None.

Funding: The Helsinki Psychotherapy Study was financially supported by the Academy of Finland (grant no 138876). The first author acknowledges the support of the Emil Aaltonen Foundation.

\begin{tabular}{|c|c|c|c|c|c|}
\hline \multirow[t]{2}{*}{ Childhood family before age 8} & 1 & 2 & 3 & 4 & 5 \\
\hline & I totally agree & I agree & I do not know & I do not agree & I definitely do not agree \\
\hline
\end{tabular}

\footnotetext{
Parental problems ${ }^{1}$

1. There was severe physical illness

2. There were long-term economic problems

3. My parents had severe conflicts

4. There was severe domestic violence between my parents

5. My mother used lots of alcohol

6. My father used lots of alcohol

7. My mother had mental problems

8. My father had mental problems

Childhood abuse ${ }^{1}$

9. Physical punishment was used

10. There was violence towards children

11. I experienced sexual harassment in my childhood family

Family unhappiness ${ }^{1,2}$

12. My family often had a good time together

13. I have lots of good memories from my childhood

14. My parents had a good relationship

15. My childhood was happy in general

16. The atmosphere in my family was very good

17. Children's welfare was important to parents
}

\footnotetext{
${ }^{1}$ The three aggregate titles were not part of the original questionnaire, but have been added here for clarity. The original questionnaire in Finnish or English is available from the authors upon request.

${ }^{2}$ The items of this aggregate were reverse-scored.
} 


\section{Supplementary materials}

Supplementary material associated with this article can be found, in the online version, at doi:10.1016/j.psychres.2018.04.011.

\section{References}

Andrews, G., Singh, M., Bond, M., 1993. The defense style questionnaire. J. Nerv. Ment. Dis. 181, 246-256.

Antonovsky, A., 1993. The structure and properties of the sense of coherence scale. Soc. Sci. Med. 36, 725-733.

APA, 1994. Diagnostic and Statistical Manual of Mental Disorders, 4th ed. American Psychiatric Association, Washington, DC.

Azim, H.F.A., Piper, W.E., 1991. The quality of object relations scale. Bull. Menninger Clin. 55, 323-333.

Bartholomew, K., Horowitz, L.M., 1991. Attachment styles among young adults: a test of a four-category model. J. Personal. Soc. Psychol. 61, 226-244.

Beck, A.T., Ward, C.H., Mendelson, M., Mock, J., Erbaugh, J., 1961. An inventory for measuring depression. Arch. Gen. Psychiatry 4, 561-571.

Benjamin, L.S., 1996. A clinician-friendly version of the interpersonal circumplex: structural analysis of social behavior (SASB). J. Personal. Assess. 66, 248-266.

Bowlby, J., 1969. Attachment and Loss Vol. 1 Basic Books, New York.

Breslow, N.E., Day, N.E., 1980. Statistical methods in cancer research. The Analysis of Case-Control Studies Vol 1 IARC Scientific Publications no 32. International Association for Research on Cancer, Lyon.

Cicchetti, D., Doyle, C., 2016. Child maltreatment, attachment and psychopathology: mediating relations. World Psychiatry 15, 89-90.

Dannehl, K., Rief, W., Euteneuer, F., 2017. Childhood adversity and cognitive functioning in patients with major depression. Child Abuse Negl. 70, 247-254.

Danese, A., McEwen, B.S., 2012. Adverse childhood experiences, allostasis, allostatic load, and age-related disease. Physiol. Behav. 106, 29-39.

Derogatis, L.R., Lipman, R.S., Covi, L., 1973. SCL-90: an outpatient psychiatric rating scale-preliminary report. Psychopharmacol. Bull. 9, 13-28.

Dienes, K.A., Torres-Harding, S., Reinecke, M.A., Freeman, A., Sauer, A., 2011. Cognitive therapy. In: Gurman, A.S., Messer, S.B. (Eds.), Essential Psychotherapies: Theory and Practice, 3rd ed. Guilford, New York, pp. 143-183.

Edwards, V.J., Holden, G.W., Felitti, V.J., Anda, R.F., 2003. Relationship between multiple forms of childhood maltreatment and adult mental health in community respondents: results from the adverse childhood experience study. Am. J. Psychiatry $160,1453-1460$

Friesen, M.D., Horwood, L.J., Fergusson, D.M., Woodward, L.J., 2017. Exposure to parental separation in childhood and later parenting quality as an adult: evidence from a 30-year longitudinal study. J. Child Psychol. Psychiatry 58, 30-37.

Gilbert, R., Widom, C.S., Browne, K., Fergusson, D., Webb, E., Janson, S., 2009. Burden and consequences of child maltreatment in high-income countries. Lancet 373, 68-81.

Greenberg, L.S., Malcolm, W., 2002. Resolving unfinished business: relating process to outcome. J. Consult. Clin. Psychol, 70, 406-416.

Hamilton, M., 1959. The assessment of anxiety states by rating. Br. J. Med. Psychol. 32, $50-55$.

Hamilton, M., 1960. A rating scale for depression. J. Neurol. Neurosurg. Psychiatry 23 $56-62$.

Heinonen, E., Heiskanen, T., Lindfors, O., Härkäpää, K., Knekt, P., 2017. Dispositional optimism as predictor of outcome in short- and long-term psychotherapy. Psychol. Psychotherapy: Theory, Research and Practice 90, 279-298.

Herman, J.L., 2008. Craft and science in the treatment of traumatized people. J. Trauma Dissoc. 9, 293-300.

Herman, J.L., Harvey, M.R., 1997. Adult memories of childhood trauma: a naturalistic clinical study. J. Trauma. Stress 10, 557-571.

Hill, C.E., Lambert, M.J., 2004. Methodological issues in studying psychotherapy processes and outcomes. In: Lambert, M.J. (Ed.), Bergin and Garfield's Handbook of Psychotherapy and Behavior Change, 5th ed. Wiley, Hoboken, pp. 84-135.

Horowitz, L.M., Alden, L.E., Wiggins, J.S., Pincus, A.L., 2000. Inventory of Interpersonal Problems. Psychological Corporation, London.

Insel, T.R., 2014. The NIMH Research Domain Criteria (RDoC) Project: precision medicine for psychiatry. Am. J. Psychiatry 171, 395-397.

Jacobsen, T., Edelstein, W., Hofmann, V., 1994. A longitudinal study of the relation between representations of attachment in childhood and cognitive functioning in childhood and adolescence. Dev. Psychol. 30, 112-124.

Kaufman, J., 2012. Child abuse and psychiatric illness. Biol. Psychiatry 71, 280-281.

Kernberg, O.F., 1984. Severe Psychiatric Disorders. Yale University Press, New Haven and London.

Knekt, P., Heinonen, E., Härkäpää, K., Järvikoski, A., Rissanen, J., Lindfors, O,, 2017. Randomized trial on the effectiveness of long- and short-term psychotherapy on psychosocial functioning and quality of life during a 5-year follow-up. Psychiatry Res. 229, 381-388.

Knekt, P., Laaksonen, M.A., Härkänen, T., Maljanen, T., Heinonen, E., Virtala, E., Lindfors, O., 2012. The Helsinki Psychotherapy Study: effectiveness, sufficiency, and suitability of short- and long-term psychotherapy. In: Levy, R.A., Ablon, J.S., Kächele, H. (Eds.), Psychodynamic Psychotherapy Research. Evidence-Based Practice and Practice-Based Evidence. Humana Press, New York, pp. 71-94.

Knekt, P., Lindfors, O., 2004. A. Randomized Trial of the Effect of Four Forms of Psychotherapy on Depressive and Anxiety Disorders. Design, Methods, and Results on the Effectiveness of Short-term Psychodynamic Psychotherapy and Solution-Focused
Therapy During a One-Year Follow-Up. Studies in Social Security and Health 77. The Social Insurance Institution, Helsinki.

Knekt, P., Lindfors, O., Keinänen, M., Heinonen, E., Virtala, E., Härkänen, T., 2017. The prediction of the level of personality organization on reduction of psychiatric symptoms and improvement of work ability in short- versus long-term psychotherapies during a 5year followup. Psychol. Psychotherapy: Theory, Research and Practice 90, 353-376.

Knekt, P., Saari, T., Lindfors, O., 2014. Intelligence as a predictor of outcome in short- and long-term psychotherapy. Psychiatry Res. 220, 1019-1027.

Knekt, P., Virtala, E., Härkänen, T., Vaarama, M., Lehtonen, J., Lindfors, O., 2016. The outcome of short- and long-term psychotherapy 10 years after start of treatment. Psychol. Med. 46, 1175-1188.

Kolk, B.A., Fisler, R.E., 1994. Childhood abuse and neglect and loss of self-regulation. Bull. Menninger Clin. 58, 145-168.

Korotana, L.M., Dobson, K.S., Pusch, D., Josephson, T., 2016. A review of primary care interventions to improve health outcomes in adult survivors of adverse childhood experiences. Clin. Psychol. Rev. 46, 59-90.

Laaksonen, M.A., Knekt, P., Lindfors, O, 2013a. Psychological predictors of the recovery from mood or anxiety disorder in short-term and long-term psychotherapy during a 3 year follow-up. Psychiatry Res. 208, 162-173.

Laaksonen, M.A., Knekt, P., Sares-Jäske, L., Lindfors, O., 2013b. Psychological predictors on the outcome of short-term psychodynamic psychotherapy and solution-focused therapy in the treatment of mood and anxiety disorder. Eur. Psychiatry 28, 117-124.

Laaksonen, M.A., Lindfors, O., Knekt, P., Aalberg, V., 2012. Suitability for Psychotherapy Scale (SPS) and its reliability, validity, and prediction. Br. J. Clin. Psychol. 51, 351-375.

Laaksonen, M.A., Sirkiä, C., Knekt, P., Lindfors, O., 2014. Self-reported immature defense style as a predictor of outcome in short-term and long-term psychotherapy. Brain Behav. 4, 495-503.

Lambert, M.J., 2013. The efficacy and effectiveness of psychotherapy. In: Lambert, M.J. (Ed.), Bergin and Garfield's Handbook of Psychotherapy and Behavior Change, 6th ed. Wiley, Hoboken, pp. 169-219.

Lindfors, O., Knekt, P., Heinonen, E., Virtala, E., 2014. Self-concept and quality of object relations as predictors of outcome in short-and long-term psychotherapy. J. Affect. Disord. 152, 202-211.

McCrory, E., De Brito, S.A., Viding, E., 2010. Research review: The neurobiology and genetics of maltreatment and adversity. J. Child Psychol. Psychiatry 51, 1079-1095.

Nanni, V., Uher, R., Danese, A., 2011. Childhood maltreatment predicts unfavorable course of illness and treatment outcome in depression: a meta-analysis. Am. J. Psychiatry 169, 141-151.

Ollila, P., Knekt, P., Heinonen, E., Lindfors, O., 2016. Patients' pre-treatment interpersonal problems as predictors of therapeutic alliance in long-term psychodynamic psychotherapy. Psychiatry Res. 241, 110-117.

Perry, J.C., Bond, M., Roy, C., 2007. Predictors of treatment duration and retention in a study of long-term dynamic psychotherapy: Childhood adversity, adult personality, and diagnosis. J. Psychiatr. Pract. 13, 221-232.

Safran, J.D., Kraus, J., 2014. Alliance ruptures, impasses, and enactments: a relational perspective. Psychotherapy 51, 381-387.

Safran, J.D, Muran, J.C., 2000. Negotiating the Therapeutic Alliance: A Relational Treatment Guide. Guilford. New York, New York

Scheier, M.F., Carver, C.S., 1985. Optimism, coping, and health: assessment and implications of generalized outcome expectancies. Health Psychol. 4, 219-247.

Shedler, J., 2010. The efficacy of psychodynamic psychotherapy. Am. Psychol. 65, 98-109.

Shiner, R.L., Masten, A.S., 2012. Childhood personality as a harbinger of competence and resilience in adulthood. Dev. Psychopathol. 24, 507-528.

Tolstoy, L., 1954. Anna Karenina (trans. R. Edmons). Penguin Books, New York Original work published 1878

Valkonen, H., Lindfors, O., Laaksonen, M.A., Knekt, P., 2012. Association between the rorschach ego impairment index (EII-2) and the level of personality organization. Psychiatry Res. 200, 849-856.

van Harmelen, A.L., van Tol, M.J., Demenescu, L.R., van der Wee, N.J., Veltman, D.J., Aleman, A., et al., 2013. Enhanced amygdala reactivity to emotional faces in adults reporting childhood emotional maltreatment. Soc. Cogn. Affect. Neurosci. 8, 362-369.

Vu, N.L., Jouriles, E.N., McDonald, R., Rosenfield, D., 2016. Children's exposure to intimate partner violence: a meta-analysis of longitudinal associations with child ad justment problems. Clin. Psychol. Rev. 46, 25-33.

Wallston, K.A., 1990. Perceived Competence Measure. Vanderbilt University, Nashville.

Wechsler, D., 1981. Manual for the Wechsler Adult Intelligence Scale - Revised. Psychological Corporation, New York.

Williams, J.M., Barnhofer, T., Crane, C., Hermans, D., Raes, F., Watkins, E., et al., 2007 Autobiographical memory specificity and emotional disorder. Psychol. Bull. 133, $122-148$.

Winer, B.J., 1971. Statistical Principles in Experimental Design, second ed. McGraw-Hill and Kogakusha, Tokyo.

Wright, M.O., Crawford, E., Del Castillo, D., 2009. Childhood emotional maltreatment and later psychological distress among college students: the mediating role of maladaptive schemas. Child Abuse Negl. 33, 59-68. 